\title{
Comparative study of Omeprazole, Rabeprazole and Ilaprazole for their efficacy in patient suffering from reflux esophagitis with symptoms.
}

\author{
Dr.Deepak Kumar ${ }^{1}$,Dr.G.P.Singh ${ }^{2}$ \\ (1.Associate Professor,S.K.Medical College,Muzaffarpur) \\ (2.Professor, S.K.Medical College,Muzaffarpur)
}

\begin{abstract}
AIM- To evaluate whether there is any difference in efficacy between three proton pump inhibitors, Omeprazole, Rabeprazole and Ilaprazole in patients of reflux esophagitis with symptoms METHODS- The study was a prospective, randomized open label comparison, total one hundred and four patients with erosive reflux esophagitis in which 32 patients(group-A) received 20mg Omeprazole, 35 patients (group-B)received 20mg Rabeprazole, 37 patients (group-C) received 10mg Ilaprazole once a day in the morning. Daily change in heart burn and acid reflux symptoms in the first 7 days of administration were assessed using a four-point scale (0: none; 1: mild; 2: moderate; 3: severe). Rate of endoscopic healing of reflux esophagitis at week 8 were also assessed between three groups. RESULTS- All the groups were well matched in terms of age, sex, $H$ pylori status, and the proportion of cases with heart burn and acid reflux symptoms before the administration of drugs. The mean heart burn scores in patients treated with Ilaprazole more rapidly decreased than those receiving Omeprazole or Rabeprazole. Complete resolution of heart burn was also more rapid in patient treated with Ilaprazole for 5 days compared with patients taking other proton pump inhibitors. Again acid reflux scores more rapidly decreased with Ilaprazole but no significant difference were seen between groups. Rate of endoscopic healing of reflux esophagitis was also more in Ilaprazole group. CONCLUSION- Ilaprazole is more effective than Omeprazole and Rabeprazole for rapid relief of heartburn, acid reflux and ulcer healing rate in patient with reflux esophagitis. Key Words:Omeprazole, Rabeprazole, Ilaprazole, Reflux esophagitis, Symptom relief.
\end{abstract}

\section{Introduction}

Hyper secretion and acid related disease are common problem in many countries [1-5 ]. Clinically,the continued hypersecretion of acid can lead to changes in the gastric epithelium, but can in more serious cases lead to erosions of the esophagus that can result in metaplasia and death.[6 ]. In an attempt to design the therapies to prevent hyperacid secretion, a variety of approaches have been used in recent years with two of the most successful being:(!) inhibition of the histamine receptor on the basolateral membrane(H2-blockers) and (2) proton pump specific drugs targeted against the $\mathrm{H}+\mathrm{K}+\mathrm{ATPase}$ (proton pump inhibitors) [7,8 ]. Both of these therapies have greatly improved the quality of life for patients suffering from this disease;however,there is an ever increasing number of patients that have experienced recurrent disease while still taking the drugs [9 ].It has been estimated that about $30 \%$ of gastroesophageal reflux disease patients remain symptomatic on the standard dose of PPI[10 ]. One explanation relates to the fact that typically PPIs have a short plasma half life, which often lead to nocturnal acid breakthrough. This increased and recurrent failure in the treatment of acid-related disease has lead to the continued development of new agents focused on faster speed of onset, while maintaining symptoms relief that remains the top prority for patients suffering from these disorders[11]. Currently,administration of therapeutic oral doses of PPIs reach steady state and thus achieve maximal effective levels after 4-5 days with typical dosing regimens[12 ]. Proton pump inhibitors (PPIs) are highly effective drugs that are widely used in the treatment ofpeptic diseases including gastric and duodenal ulcer (DU), reflux oesophagitis and Zollinger-Ellison syndrome.[13-15] Many new therapeutic drugs with similar structures and better therapeutic outcomes have been developed since omeprazole was first introduced into the market. These newdrugs include rabeprazole, pantoprazole, lansoprazole, esomeprazole and the new moleculeilaprazole $\{2$ [[(4-methoxy-3-methyl)-2-pyridinyl]methylsulfinyl-5-(1Hpyrrol- 1-yl)-1H-benzimidazole,CAS 172152-36-2)\}. It was also called IY81149 (before, MW366.4) which was developed by Il YangPharmacy Co. (Seoul, Korea) and was first studied in vivo via experimental animal models ofmouse, rats, dogs and pigs.[16-18] These studies found that ilaprazole significantly prevented thedevelopment of reflux oesophagitis and gastric secretion in a dose-dependent manner, and atthe same time had little effect on the animal's cardiovascular system, autonomic nervous systemor smooth muscle function from 0.3 to $1000 \mathrm{mg} / \mathrm{kg}$, indicating that ilaprazole has a broad doserange and safety feature.[19,20]There was only one clinical study on patients with gastrooesophagealreflux 
disease, which showed that administration of 10 and $20 \mathrm{mg}$ ilaprazole produceda statistically significantly greater and prolonged suppression of gastric $\mathrm{pH}$ than $20 \mathrm{mg}$ Omeprazole.[21].Healing of reflux esophagitis is directly correlatedwith the intragastric $\mathrm{pH}>4.0$. The efficacy ofantisecretory drugs in healing reflux esophagitis dependson the strength and duration of acid suppression withina $24 \mathrm{~h}$ period, and the duration of the treatment[22-24].The time period required to obtain maximal inhibitionof gastric acid secretion is, however, reported to differbetween PPI[25-27]. As thequality of life (QOL) of patients with reflux esophagitisis decreased by heartburn symptoms, quick symptomrelief is important to normalize their QOL.[28,29]In this study, weinvestigated the differences in symptom relief in thefirst $7 \mathrm{~d}$ of administration of Omeprazole, Rabeprazole and Ilaprazole in patients with reflux esophagitis.

\section{Materials And Methods}

STUDY DESIGN- We undertook randomized open level comparative study of three groups of patients with endoscopic proven reflux esophagitis in S.K.Medical college, Muzaffarpur from March 2012 to August 2013. Total one hundred and four patients were recruited for this study. Eight of the patients were lost to follow up, who refused endoscopic examination after administration of drugs . Subjects with active peptic ulcer, hepatic, renal, cardiac disease, anemic, pregnant, lactating, malignant disease were excluded.

STUDY PROCEDURE- After taken written informed consent patients were screened for selection criteria. Group A(Omeprazole group) comprising of 32 patients were taking 20mg Omeprazole, Group-B(Rabeprazole group) comprising of 35 patients were taking $20 \mathrm{mg}$ Rabeprazole, Group-c (Ilaprazole group) comprising of 37 patients were taking 10mg Ilaprazole all once in the morning. 2 patients in Group-A, 4 patients in Group-B, 2 patients in Group-C were lost to follow up who refused endoscopic examination after administration of drugs. Patients were not allowed to take $\mathrm{H} 2$ blocker, antacids, or prokinetic drugs during the study period.All endoscopic examinations were performed by high resolution upper gastrointestinal endoscope(Olympus,Tokyo,Japan) before and $8 \mathrm{wk}$ after administration of PPI. H Pylori infection status was tested by measuring serum anti-H pylori immunoglobulin IgG antibodies, using an Elisa test. All patients were asked to keep a symptoms diary, in which they recorded the severity of symptoms (heart burn and acid reflux) prior to and during first 7 days of drugs administration. The severity of symptoms was graded on a four point scale( 0 :none; 1 :mild; 2 :moderate; 3 :severe). Mild symptoms were defined as a heart burn /acid reflux that did not disturb the normal daily activity of the patients. Moderate symptoms were defined as those that bothered the daily activity, while the patients continued to work positively. Severe symptoms were defined as high grade symptoms that stopped the daily productive activity of the patients. The patients were instructed to record the severity of the symptoms as a whole previous days score in the following morning. The daily changes in the severity of two symptoms (heart burn and acid reflux) were separately analyzed.

STATISTICAL ANALYSIS- Statistical analysis of inter-group data was performed using the Microsoft office excel F-test. Complete disappearance of symptoms between the groups were also compared by Microsoft office excel F-test. Age, Sex, H. pylori status were analyzed by $x^{2}$ test.

\section{Results}

Table -1 Baseline characteristics of the patients

\begin{tabular}{|l|l|l|l|l|}
\hline Groups & \multicolumn{1}{|c|}{$\begin{array}{c}\text { Group-A(Omeprazole) } \\
\mathrm{n}=32\end{array}$} & \multicolumn{1}{|c|}{$\begin{array}{c}\text { Group-B(Rabeprazole) } \\
\mathrm{n}=35\end{array}$} & $\begin{array}{c}\text { Group-C (Ilaprazole) } \\
\mathrm{n}=37\end{array}$ & $\begin{array}{c}\text { Statictical } \\
\text { difference }\end{array}$ \\
\hline Age(mean \pm SD) & $55.6 \pm 8.7$ & $56.4 \pm 7.6$ & $55.3 \pm 9.2$ & NS \\
Sex(male/female) & $17 / 15$ & $17 / 18$ & $19 / 18$ & NS \\
H pylori (positive/negative) & $12 / 20$ & $10 / 25$ & $13 / 24$ & NS \\
$\begin{array}{l}\text { Symptoms } \\
\text { Heart burn(\%) }\end{array}$ & & $31(88.5)$ & $33(89.1)$ & NS \\
Acid reflux(\%) & $27(84.4)$ & $16(45.7)$ & $17(45.9)$ & NS \\
\hline
\end{tabular}

NS- Not significant

Table-1 Summarizes the baseline characteristics of the patients enrolled for this study. There were no significant difference between groups in sex, age, $\mathrm{H}$ pylori status and the proportion of cases with heart burn and acid reflux symptoms before the administration of drugs. 


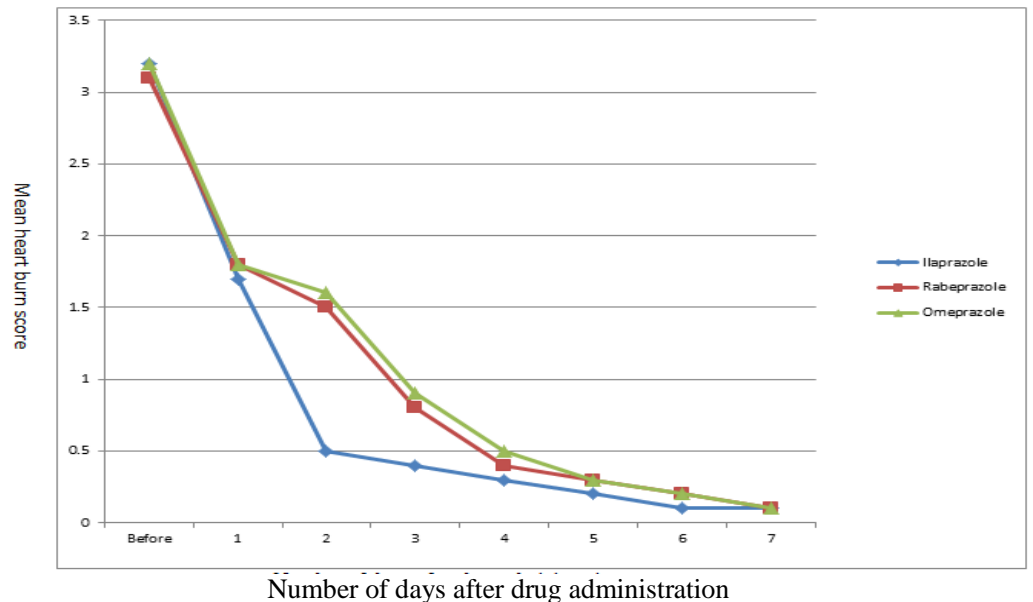

Figure-1 Daily changes in mean heartburn score for all patients in eachgroups

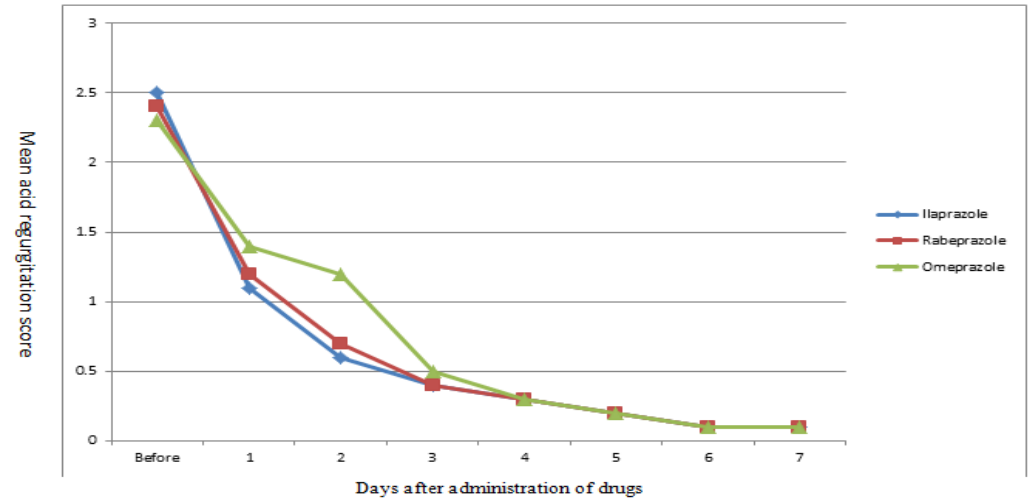

Figure-2 Daily changes in mean acid regurgitation score for all patients in each group

Figure- 1 and 2 shows the daily changes in the mean scores of heartburn and acid reflux. The heartburn scores were significantly lower in patients administered Ilaprazole after first and second days than in those administered Omeprazole and Rabeprazole respectively. The difference in heartburn between groups tended to disappear after 5 days of administration of test drugs. Complete disappearance of heartburn symptoms after administration of test drugs from I day to 5 day occurred more rapidly in patients administered Ilaprazole than those administered Omeprazole ( $\mathrm{P}=0.0016, \mathrm{P}=0.0096, \mathrm{P}=0.0028, \mathrm{P}=0.00136, \mathrm{P}=0.0068$ respectively) and Rabeprazole $(\mathrm{P}=0.0021, \mathrm{P}=0.0042, \mathrm{P}=0.0036, \mathrm{P}=0.0014, \mathrm{P}=0.0072$ respectively $)$. No significant difference in acid reflux scores were seen between the groups(Figure-2)

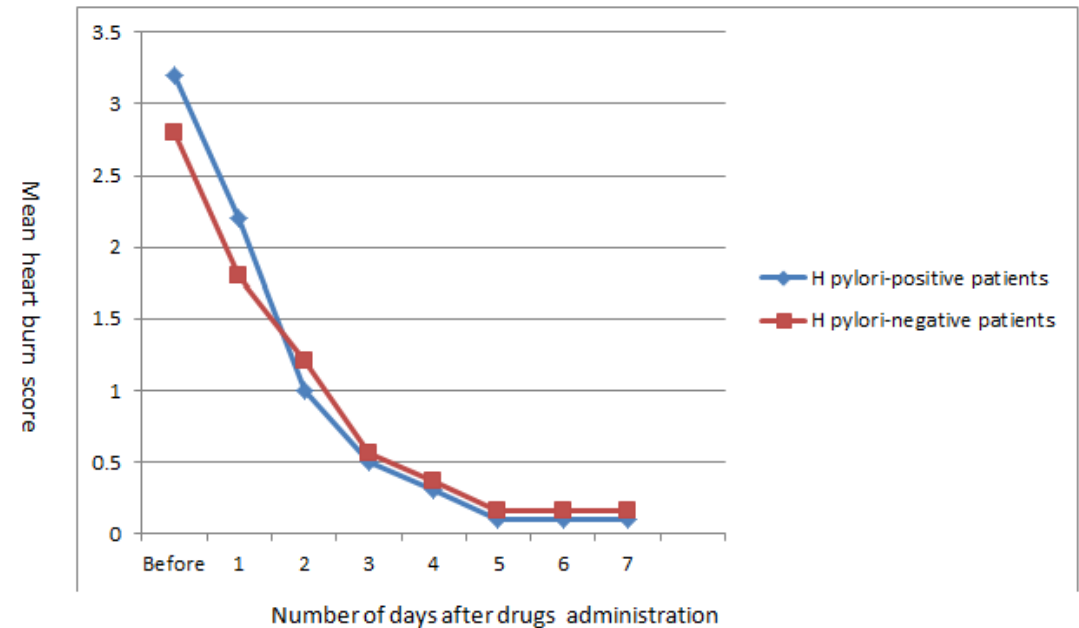

Figure-3 Daily changes in mean heartburn scores in $H$ pylori-postive and $H$ pylori negative Patients in each group 
The daily changes in heartburn scores during the first week of administration of test drugs did not differ between $\mathrm{H}$ pylori-positive and $\mathrm{H}$ pylori-negative patients by F-test. There was no significant difference in the complete disappearance of heartburn between $\mathrm{H}$ pylori-positive and $\mathrm{H}$ pylori-negative patients(Fig-3)

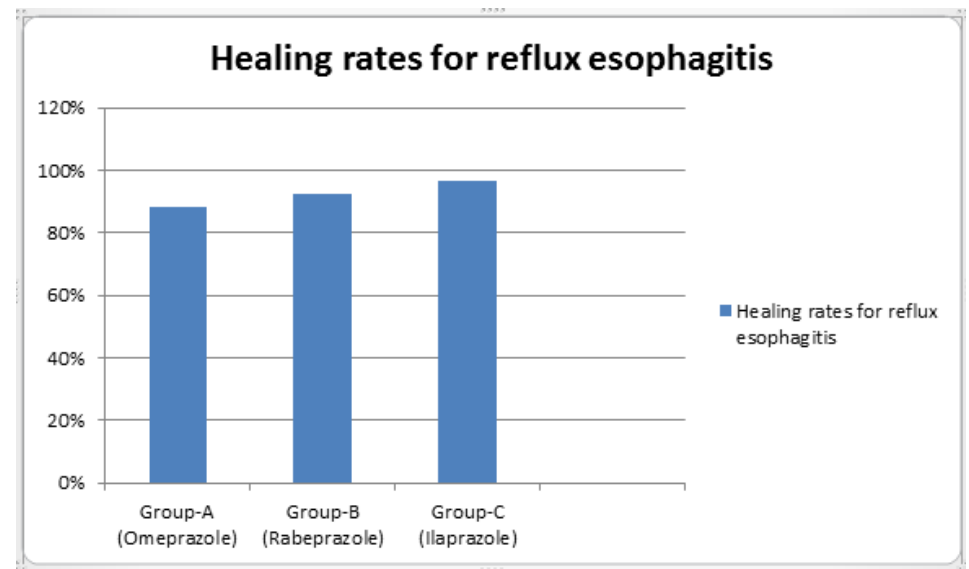

Figure-4 Percentage of Healing rate in each group after taking drug

Eight of the 104 patients enrolled in the present study refused endoscopic examination after administration of PPI, so upper gastrointestinal endoscopy was performed in 96 patients at week 8 after commencement of drugs. The endoscopic healing rates for reflux esophagitis in patients administered Omeprazole, Rabeprazole and Ilaprazole were $88 \%, 92.6 \%$ and $96.7 \%$ respectively(Fig-4).

\section{Discussion}

Acid secretion is an essential component of the digestive process and provide both concentrated acid enzyme to aid in the breakdown of foodstuffs into components that can be absorbed in the intestine[30]. But in some patients this process does not work properly leading to hypersecretion of acid causing symptomatic pain and discomfort [30,31]. The risk of erosion of epithelia and internal bleeding climb dramatically when this hypersecretion occurs for long period of times. In an effort to combat the effects of this hypersecretion, a wide variety of agents have been proposed that either block the histamine receptors, or target the acid extrusion pump[32]. Of these various agents, the members of the Omeprazole class of compounds targeting the pump have been highly successful in providing inhibition of acid secretion. The symptoms of reflux esophagitis, such as heartburn, have been demonstrated to markedly impair QOL in these patients[33,34]. A multicentric trial conducted by Wang et al35] in 2011 confirmed ilaprazole as an effectivegastric acid suppressor; gastric acid suppression increased with the increasing dose of ilaprazole, viz. $5 \mathrm{mg}, 10 \mathrm{mg}$ and $20 \mathrm{mg}$.Two registered trials evaluated the efficacy in terms of symptom relief through a graded score technique which served as a secondary end-point. Wang et al.[36] and Ho et al.[37] concluded that a majority of patients (>75\%) became asymptomatic after treatment with ilaprazole.In the present study, we compared with efficacy of Omeprazole, Rabeprazole and Ilaprazolefor symptom relief in the first $7 \mathrm{~d}$ of treatment for refluxesophagitis. The administration of Ilaprazole was most effective for symptom relief within $2 \mathrm{~d}$ compared with Omeprazole and Rabeprazole administration,this difference disappeared $5 \mathrm{~d}$ after commencement of drug administration.

In the present study, we demonstrated that Ilaprazole gave faster symptom relief than Rabeprazole and Omeprazole. Because Ilaprazole hasbeen shown to have a faster onset of antisecretory activity than Omeprazole and Rabeprazole.

Ilaprazole rapidly increased the detectable intragastric $\mathrm{pH}>4$ on the first treatment day, and the first $5 \mathrm{~d}$ after commencement of administration of Ilaprazole, and the intragastric $\mathrm{pH}>4$ maintained for a longer period of time than Rabeprazole and Omeprazole.

Although the symptom relief was faster by administration of Ilaprazole than by Omeprazole and Rabeprazole, the three kinds of PPI investigated in the present study were demonstrated to be effective for symptom relief within 1 wk in patients with endoscopically proven esophagitis. Recently, PPI has been also used for the diagnosis of gastroesophagealreflux, not only in the patients with non-erosive reflux disease (NERD)[38,39], but also in patients with atypical gastroesophageal reflux symptoms[40,41].

The healing rate of reflux esophagitis after $8 \mathrm{wk}$ of treatment tended to be higher in patients administered Ilaprazole than in those administered Omeprazole and Rabeprazole, although these differences did not reach a statistically significant level. However, these differences need to be confirmed by further large comparative studies, which may have been caused by variations in the proportion of $H$ pylori positive patients between the four PPI regimen groups, because $H$ pylori infection has been reported to influence the healing of reflux 
esophagitis by PPI[42]. The degree of symptom relief was not, however, different during the first week of administration of PPI between $H$ pylori positive and negative patients. The symptomatic response to PPI treatment during the first week administration should not, therefore, be affected by $H$ pylori status.

There were several limitations in the comparison ofthe speed of symptom relief between the three PPIs inthe present study since the study subjects were relativelysmall in number.

\section{Conclusion}

The present study found that Ilaprazole $10 \mathrm{mg}$ daily may be more effective than either Omeprazole 20 $\mathrm{mg}$ daily or Rabeprazole $20 \mathrm{mg}$ daily for the rapid relief ofheartburn symptoms in patients with endoscopically proven reflux esophagitis. Symptom relief after several days of treatment and reflux esophagitis healing ratesafter 8 wk of treatment, were not different between patients treated with Omeprazole, Rabeprazole or Ilaprazole.

\section{References}

[1]. Aihara T, Nakamura E, Amagase K et al.Pharmacological control of gastric acid secretion for the treatment of acid-related peptic disease: past, present, future. Pharmcol Ther 2003;98:109-27.

[2]. Gardner JD,Sloan S, Miner PB et al. Meal- stimulated gastric acid secretion and integrated gastric acidity in gastroesophagealreflux disease. Aliment Pharmacol Ther 2003;17:945-53

[3]. Williams JL. Gastroesophageal reflux disease: Clinical manifestations. Gastroenterol Nurs 2003;26:195-200

[4]. Lehmann F, Hildebrand P, Benglinger C, New molecular targets for treatment of peptic ulcer disease. Drugs 2003;63:1785-97.

[5]. Eisen GM, Sandler RS, Murray S et al. The relationship between gasto-esophageal reflux disease and its complications with Barrett's esophagus. Am J Gastroenterol 1997;92:27-31.

[6]. Torcotte S, Duranceau A, Gastroesophageal reflux and cancer. Thorac Surg Clin 2005;15:341-52.

[7]. Robinson M. Proton pump inhibitors: update on their role in acid-related gastrointestinal disease. Int J Clin Pract 2005;59:709-15

[8]. Garnett WR. Lansoprazole a proton pump inhibitor. Ann Pharmacother 1966;30:1425-36.

[9]. Katz PO.HatlebakkJG,Castell DO. Gastric acidity and acid break through with twice -daily Omeprazole or Lansoprazole. Aliment Pharmacol Ther 2000;14:709-14.

[10]. Carlsson R, Galmiche JP, Dent J et al. Prognostic factors influencing relapse of oesophagitis during maintanence therapy with antisecretory drugs: a meta-analysis of long term omeprazole trials. Aliment Pharmacol Ther 1997;11:473-82.

[11]. Kleiman L, McIntosh E, Ryan M et al. Willingness to pay for complete symptoms relief of gastroesophageal reflux disease. Arch Intern Med 2002;162:1361-6.

[12]. Tytgat GN. Shortcoming of the first-generation proton pump inhibitors. Eur J Gastroenterol Hepato 2001;13(Suppl 1):S29-33.

[13]. Welage LS, Berardi RR. Evaluation of omeprazole, lansoprazole, pantoprazole, andrabeprazole in the treatment of acid-related diseases. J Am Pharm Assoc (Wash).2000;40:52-62 quiz 121-3.

[14]. Welage LS. Pharmacologic properties of proton pump inhibitors. Pharmacotherapy.2003;23:74S-80S.

[15]. Dekel R, Morse C, Fass R. The role of proton pump inhibitors in gastro-oesophageal refluxdisease. Drugs. 2004;64:277-95.

[16]. Kil BJ, Kim IW, Shin CY, Jeong JH, Jun CH, Lee SM, et al. Comparison of IY81149 withomeprazole in rat reflux oesophagitis. J Auton Pharmacol. 2000;20:291-6.

[17]. Kwon D, Chae JB, Park CW, Kim YS, Lee SM, Kim EJ, et al. Effects of IY -81149, a newlydeveloped proton pump inhibitor, on gastric acid secretion in vitro and in vivo.Arzneimittelforschung. 2001;51:204-13.

[18]. Kim EJ, Lee RK, Lee SM, Kim DY. General pharmacology of IY- 81149, a new proton pumpinhibitor. Arzneimittelforschung. 2001;51:51-9.

[19]. Periclou AP, Goldwater R, Lee SM, Park DW, Kim DY, Cho KD, et al. A comparativepharmacodynamic study of IY-81149 versus omeprazole in patients with gastroesophagealreflux disease. Clin Pharmacol Ther. 2000;68:304-11.

[20]. Holloway RH, Dent J, Narielvala F, Mackinnon AM.Relation between oesophageal acid exposure and healing ofoesophagitis with omeprazole in patients with severe refluxoesophagitis. Gut 1996; 38: 649-654

[21]. Johansson KE, Ask P, Boeryd B, Fransson SG, TibblingL. Oesophagitis, signs of reflux, and gastric acid secretionin patients with symptoms of gastro-oesophageal refluxdisease. Scand J Gastroenterol 1986; 21: 837-847

[22]. Bell NJ, Hunt RH. Role of gastric acid suppression in the treatment of gastro-oesophageal reflux disease. Gut 1992; 33:118-124

[23]. Besancon M, Simon A, Sachs G, Shin JM. Sites of reactionof the gastric H,K-ATPase with extracytoplasmic thiolreagents. $J$ Biol Chem 1997; 272: 22438-22446

[24]. illiams MP, Sercombe J, Hamilton MI, Pounder RE.A placebo-controlled trial to assess the effects of 8 daysof dosing with rabeprazole versus omeprazole on 24-hintragastric acidity and plasma gastrin concentrations inyoung healthy male subjects. Aliment Pharmacol Ther 1998;12: 1079-1089

[25]. Wi 11 i ams MP, Pounde r RE. Revi ew a r t i c 1 e : the pharmacology of rabeprazole.AlimentPharmacol Ther 1999;13Suppl 3: 3-10

[26]. Gardner JD, Perdomo C, Sloan S, Hahne WF, Barth JA,Rodriguez-Stanley S, Robinson M. Integrated acidity andrabeprazole pharmacology. Aliment Pharmacol Ther 2002; 16:455-464

[27]. Saitoh T, Fukushima Y, Otsuka H, Hirakawa J, Mori H,Asano T, Ishikawa T, Katsube T, Ogawa K, Ohkawa S.Effects of rabeprazole, lansoprazole and omeprazole on intragastric $\mathrm{pH}$ in CYP2C19 extensive metabolizers. AlimentPharmacol Ther 2002; 16: $1811-1817$

[28]. Dimenas E. Methodological aspects of evaluation ofQuality of Life in upper gastrointestinal diseases. Scand JGastroenterol Suppl 1993; 199: 18-21

[29]. Dimenas E, Carlsson G, Glise H, Israelsson B, Wiklund I.Relevance of norm values as part of the documentation ofquality of life instruments for use in upper gastrointestinaldisease. Scand JGastroenterol Suppl 1996; 221: 8-13

[30]. GiebalJP,Wagner C. An update on acid secretion.Rev Physiol Biochem Pharmacol 2006;156:45-60

[31]. Hersey SJ,SachsG.Gastric acid secretion. Physiol Rev1995;75:155-89.

[32]. Sachs G, Munson K, Hall K et al. Gastric H+K+ ATPase as a therapeutic target in peptic ulcer disease. Dig Dis Sci 1990;35:153744.

[33]. Dimenas E. Methodological aspects of evaluation of Quality of Life in upper gastrointestinaldiseases. Scand JGastroenterol Suppl 1993; 199: 18-21 
[34]. Dimenas E, Carlsson G, Glise H, Israelsson B, Wiklund I. Relevance of norm values as part of the documentation of quality of life instruments for use in upper gastrointestinal disease. Scand J Gastroenterol Suppl 1996; 221: 8-13

[35]. Wang L, Zhou L, Lin S, Hu H, Xia J. A new PPI, ilaprazole compared with omeprazole in the treatment of duodenal ulcer: a randomized double-blind multicenter trial. J Clin Gastroenterol. 2011;45:322-9.

[36]. Wang L, Zhou L, Hu H, Lin S, Xia J. Ilaprazole for the treatment of duodenal ulcer: a randomized, double-blind and controlled phase III trial. Curr Med Res Opin. 2012;28:101-9.

[37]. Ho KY, Kuan A, Zaño F, Goh KL, Mahachai V, Kim DY, et al. Randomized, parallel, double-blind comparison of the ulcer healing effects of ilaprazole and omeprazole in the treatment of gastric and duodenal ulcers. J Gastroenterol. 2009;44:697-707.

[38]. Johnsson F, Weywadt L, Solhaug JH, Hernqvist H, Bengtsson L. One-week omeprazole treatment in the diagnosis of gastrooesophageal reflux disease. Scand JGastroenterol 1998; 33: 15-20

[39]. Fass R, Ofman JJ, Sampliner RE, Camargo L, WendelC, Fennerty MB. The omeprazole test is as sensitive as24-h oesophageal pH monitoring in diagnosing gastrooesophageal reflux disease in symptomatic patients with erosive oesophagitis. Aliment Pharmacol Ther 2000; 14: 389-396

[40]. Meier JH, McNally PR, Punja M, Freeman SR, Sudduth RH, Stocker N, Perry M, Spaulding HS. Does omeprazole (Prilosec) improve respiratory function in asthmatics with gastroesophageal reflux? A double-blind, placebo-controlled crossover study. Dig Dis Sci 1994; 39: 2127-2133

[41]. Hanson DG, Kamel PL, Kahrilas PJ. Outcomes of antireflux therapy for the treatment of chronic laryngitis. Ann OtolRhinol Laryngol 1995; 104: 550-555

[42]. Holtmann G, Cain C, Malfertheiner P. Gastric Helicobacter pylori infection accelerates healing of reflux esophagitis during treatment with the proton pump inhibitor pantoprazole. Gastroenterology 1999; 117: 11-16 